\title{
Straff-välfärdsstaten och kontrollkultur i svensk kriminalpolitik $^{*}$
}

\author{
Av Henrik Tham, professor em., Kriminologiska institutionen, \\ Stockholms universitet
}

\begin{abstract}
Swedish criminal policy has changed markedly in the years following World War II. This change shows clear parallels to the processes described in David Garland's The Culture of Control. The current analysis, however, indicates that developments in Sweden differ in important ways from processes discussed by Garland. First, Garland's hypotheses concerning factors that tend to increase crime and the fear of crime do not hold true for Sweden. Second, the notion that an increasingly punitive population has pressured its political representatives for more penal legislation and more prisons is not supported by the Swedish data. Third, the movement toward a harsher criminal policy may actually have resulted from dynamics within the welfare state itself. The punitive turn should therefore be understood as a political change from above rather than a cultural change from below.
\end{abstract}

\section{Garlands The Culture of Control}

David Garlands The Culture of Control har sedan sekelskiftet blivit den centrala referenspunkten i kriminalpolitisk forskning. Även om verket bygger på angloamerikanska länder, har analysen uppenbart värde för förståelsen av utvecklingen i andra länder. Samtidigt är varken utvecklingen eller dess bestämningsfaktorer identiska. Frågan kan därför ställas hur Garlands analys av kriminalpolitiken är tillämplig för en nordisk välfärdsstat, i detta fall Sverige. Centralt i denna fråga är då om förändringen av kriminalpolitiken i en mer straffande riktning ska förstås som en kulturell förändring, det vill säg att den drivits fram av förändringar i det allmänna rättsmedvetandet, eller om det finns alternativa förklaringar för Sverige till Garlands kulturtes.

Garland börjar med en beskrivning av straff-välfärdsstaten (penal-welfare state) som präglade kriminalpolitiken decennierna närmast efter andra världskri-

* Title in English: The penal-welfare state and culture of control in Swedish criminal policy 
get. Denna modell utmärktes av en närmast hegemonisk föreställning om möjligheten till behandling och rehabilitering av den enskilde lagöverträdaren. Stor tilltro knöts till experter. Brott och missbruk sågs som symtom på brister i samhället. Dessa skulle rättas till genom social ingenjörskonst. Den allmänna politiken riktades in på att förändra förhållanden som så tydligt var förknippade med brottslighet som fattigdom, trångboddhet, arbetslöshet, bristande utbildning och ojämlikhet. Kriminalpolitiken var ett tydligt utryck för modernismen.

Straff-välfärdsstaten kom från slutet av 1960-talet under attack. Behandlingstänkandet med tidsobestämda påföljder framställdes alltmer som orättvist. Det kunde verka ras- och klassmässigt diskriminerande. Till detta kom effektivitetsfrågan. Nothing works blev en syn som slog starkt igenom vad gällde synen på behandlingsprogram.

Behandling och social ingenjörskonst hade heller inte kunnat stoppa brottsökningen. Mot bakgrund av denna utveckling ökade, enligt Garland, rädslan för brott i medelklassen som ställde krav på politikerna att göra något. Politikerna svarade genom att lyfta fram brottsoffret, utveckla en expressiv retorik, skilja mellan »vi och dom«, och generellt definiera kriminalpolitiken i termer av lag och ordning. Där tidigare lagöverträdaren stod i centrum som objekt för rehabilitering och återintegrering blev i stället allmänhetens skydd kriminalpolitikens mål. En ny brottskontrollkultur hade fötts (Garland 2001, s. 174 ff.).

\section{Likheter ...}

Likheterna mellan utvecklingen i Sverige och den i Garlands analys är påtagliga. Fram till slutet av 1960-talet var brottsligheten inte en politisk fråga trots att brottsökningen under de två decennierna efter andra världskriget var den kraftigaste på hundra år. Kriminalpolitiken drevs av intresserade experter som ämbetsmän, forskare och läkare, och arbetet präglades av en stark tilltro till vetenskapen och möjligheten att finna rationella lösningar på brottsproblemet. Förväntningarna på det nya ämnet kriminologi var stora. Kriminalpolitiken sågs inte som politik (Tham 2018, s. 20 ff.).

Kritiken började med KRUM, Riksförbundet för kriminalvårdens humanisering, som bildades 1966. Liksom i Garlands analys framhöll förbundet de tidsobestämda straffens orättvisa och att de fattiga fick sitta inne längre. KRUM ansåg inte heller att rehabilitering framgångsrikt kunde bedrivas i fängelse. Kritiken kom även från juridiskt håll. Brottsförebyggande rådet tillsatte en arbetsgrupp med liberalt sinnade jurister som 1977 kom med rapporten Nytt straffsystem (Brå 1977). Där lanserades straffvärde som princip för dömande i stället för rehabilite- 
ring, och det framhölls att fängelse inte skulle kunna berättigas genom hänvisning till behandlingsbehov.

1980-talet blev en kriminalpolitisk brytningsperiod. Liberala idéer från 70talet gjorde sin marsch genom kommittéerna och resulterade i betänkanden som försökte begränsa användningen av frihetsstraff. När straffvärdesprincipen för dömande blev lag 1989 hade dock den kriminalpolitiska vinden vänt. Betoningen av brottets svårhet och vikten av straffet i sig kom alltmer att tjäna som motiv för skärpningar av själva strafflagstiftningen (Tham 2018, s. 84 ff.).

Brottsoffret, som tidigare varit en icke-fråga, träder mot slutet av 80-talet allt tydligare fram i den offentliga debatten och får så gott som alltid berättiga höjningar av straffskalorna. Strafflagstiftningens expansion börjar redan under senare delen av 70-talet och ökar kraftigt efter sekelskiftet. Ned- och avkriminaliseringar, som tydligt präglade utveckling fram till mitten av 70-talet försvinner nu nästan helt. Den kriminalpolitiska retoriken gör helt om. Den tidigare optimismen förbyts i pessimism, och ledande politiker hänvisar till brottsligheten som lett till ett Sverige som är alltmer brutalt, som befinner sig i »civilisatoriskt förfall« och som riskerar att inte hålla samman utan fler poliser och mer fängelser (Tham 2018, s. 80). ${ }^{1}$

\section{... och skillnader}

Samtidigt som den utveckling Garland beskriver uppvisar påtagliga likheter med situationen i Sverige finns också tydliga skillnader. Garland anger den ökande brottsligheten som skäl till ökad rädsla och krav från medelklassen på politikerna att gripa in mot brottsligheten. Problemet är att brottsligheten inte ökar. Olika mått pekar i och för sig i olika riktningar, men centrala indikatorer anger en utplanande och till och med minskande brottslighet. Allt färre unga i Sverige begår brott vilket framgår av lagföringsstatistik, kohortdata och uppgifter om självdeklarerad brottslighet. Våldsbrottsligheten har inte ökat enligt olika surveyundersökningar, sjukhusuppgifter eller dödlighetsdata. Återfallen i kriminalvårdspåföljder går tillbaka (Tham 2018, kap. 2).

Det kan nu kanske invändas att Garlands bok kom 2001 och att situationen har ändrats sedan dess. Det stämmer att bilden av en stagnerande eller minskande brottslighet blivit allt tydligare över tid. Denna utveckling var dock fullt märkbar i flera länder innan sekelskiftet, och det gäller även i USA och Storbritannien

1. För att hålla antalet referenser nere hänvisas i flera fall till Tham 2018 för närmare referenser, inklusive till olika sifferserier. 
(Tonry 2014) som är de länder som ligger till grund för Garlands analys. Av de diagram som inkluderats i boken framgår också tydligt den stagnerande brottsligheten i både USA, sedan 1980-talet, och Storbritannien, sedan 1990-talet (Garland 2001, s. 208).

Den ökande rädslan för brott är central hos Garland. I Sverige har rädslan enligt olika mått ökat sedan 2015 men har dessförinnan legat relativt stabilt. Upptagenheten av lag och ordning som ett viktigt samhällsproblem har trendmässigt minskat sedan mätningarna inleddes i slutet av 80-talet men vänder upp 2016 (Tham 2018, s. 46 ff.).

Garland skrev mot bakgrund av den historiskt exceptionella ökningen av fängelserna i USA och även i England som hade den högsta fångpopulationen i Västeuropa som också steg markant (Garland 2001, s. 209). I Sverige ligger fängelsebeläggningen, i förhållande till folkmängden, på ungefär samma nivå på 2010talet som på 1960-talet. Den fördubbling av fångtalen i Sverige som skedde de två decennierna efter andra världskriget förbyttes på 70-talet $\mathrm{i}$ en nedgång. Efter en trendmässig ökning fram till 2009 har fängelsebeläggningen minskat med mer än en femtedel.

Slutligen, ett särskilt brott som inte får någon plats hos Garland men som spelat stor roll i den svenska utvecklingen är narkotikabrott. Från 1960-talets slut fram till sekelskiftet kan detta brott sägas ha varit motorn i kriminalpolitiken. Upp till 30 procent av alla intagna i fängelse har haft narkotikabrott som huvudbrott. Fängelselagen har skärpts med hänvisning till narkotika, hemlig avlyssning av elektronisk kommunikation har berättigats främst på grund av de påstådda riskerna med narkotika, och kärnan i den grova organiserade brottsligheten, ett begrepp som alltmer kommit att dominera kriminalpolitiken, är narkotikaförsäljningen (Tham 2018, kap. 5).

\section{Förklaringar till kontrollkulturens uppkomst}

Den kriminalpolitiska utveckling som ägt rum i de angloamerikanska länderna respektive Sverige uppvisade trots skillnader klara likheter som bör kunna förklaras. Garlands förklaring av den kriminalpolitiska utvecklingen ligger delvis i själva beskrivningen. Den tilltagande betoningen av lag och ordning utvecklas i ett dialektiskt förhållande mellan brott och kontroll. Brottskontrollen anpassas till det senmoderna samhället där medborgarna ställer krav på ökad individuell frihet och mer konsumtion. Den minskande kontrollen leder dock till avvikelser i form av brott och drogmissbruk. Samtidigt ökar ojämlikheten och utestänger resurssvaga grupper från konsumtionen och hänvisas till brott för försörjning. Detta förstärker ytterligare kraven på kontroll av brott och medelklassens skydd mot de fattiga. 
Frågan om Garlands förklaringar till kriminalpolitikens utveckling är användbara för Sverige beror dels på om förklaringarna alls håller, dels på om angloamerikanska förhållanden är giltiga även i andra länder. Garlands breda beskrivning förefaller allmänt sett rimlig. Samtidigt är förklaringarna svåra att pröva, då nästan allt kommer med i framställningen. Det är få förhållanden som inte bidrar till förklaringen av utvecklingen, och olika processer påverkar och förstärker varandra ömsesidigt.

Garland tar upp medias och särskilt TV:s roll för att förstå kriminalpolitiken. Denna utveckling har rimligen också varit viktig i Sverige. Bilden av mediernas betydelse är delvis motsägelsefull, men forskning tyder på en utveckling mot ökad »sensationalism« och en »uppmjukning« av fakta (Schwarz \& Hammarlund 2018). Människors oro för brott följer enligt en känd studie inte brottsutvecklingen utan medias rapportering och politiska utspel (Beckett 1997). Privatiseringen av TV-kanaler inleds i Sverige på 1980-talet samtidigt som svängningen i en mer alarmistisk riktning blir synlig i kriminalpolitiken (von Hofer \& Tham 2013, s. 43). Beskrivningen av brottsligheten i pressen förändras också tydligt i negativ riktning under samma tid (Pollack 2001).

Brottskontrollen har, enligt Garland, sina strukturella bestämningar. Det senmoderna samhället är ett risksamhälle, såväl socialt som ekonomiskt. Drag i samhällsutveckling som bidragit till ökningen av både brott och straff är bland annat ökad arbetslöshet, ökad familjeupplösning, ökad segregation, ökad upplevelse av relativ deprivation på grund av medias utveckling och en nedbrytning av traditionella auktoritetskällor.

Dessa ganska allmänna förklaringar till brottsutvecklingen ska inte diskuteras för Sveriges del. I den mån samhället utvecklats som Garland påstår och om dessa förhållanden är brottsalstrande har brottsökningen i huvudsak uteblivit. Analysen överdeterminerar brottsutvecklingen givet den stagnation av brottsligheten som inträffat redan före sekelskiftet i både USA och Storbritannien. Om samhällsutvecklingen också skulle ha påverkat oron för brott, så presenteras inga sådana systematiska mått över tid i analysen.

Inte heller ger Garland några data som skulle tyda på att allmänheten skulle blivit mer straffinriktad - vilket han till och med själv tillstår saknas i framställningen (Garland 2001, s. 260, not 29). I Sverige liksom i de övriga nordiska länderna genomfördes en stor undersökning av det allmänna rättsmedvetandet med data från främst 2009. Resultatet blev att allmänheten i genomsnitt låg på samma straffnivå eller under den som domstolarna ansåg vara rimlig (Jerre \& Tham 2010; Balvig et al. 2015). Denna undersökning genomfördes bara vid ett tillfälle varför det förstås inte går att säga om medborgarnas krav på straff ökat. Politiker- 
nas hänvisning till folkets krav för skärpt strafflagstiftning har dock knappast empiriskt stöd.

Garland framhåller den nya brottskontrollen som politiserad och populistisk (s. 13). Flera andra författare har gjort samma iakttagelse (t.ex. Pratt 2007; Loader \& Sparks 2011). Fakta förnekas, emotionella argument får företräde framför rationella, orsaken till brott är individuell brist på moral, alarmistiska uttalanden är legio och »folket« är den yttersta auktoriteten vars vilja tolkas av politikerna. Han stannar dock vid att beskriva just kriminalpolitiken som populistisk. Det blir ytterligare en beskrivning om än träffande och giltig även för Sverige.

Utvecklingen av kriminalpolitiken i populistisk riktning som förklaring skulle stärkts om den kopplats till utvecklingen av politiken generellt. Dagens politik i flera väststater inklusive Sverige har allmänt sett blivit alltmer populistisk. Politiken till skillnad från för 50 år sedan karaktäriseras av en emotionell ton och användningen av media och reklam, av framhållandet av skillnader i (nationella) värden i stället för skillnader i klass, av moraliska förklaringar i stället för strukturella, av en betoning av risk och fara och av skildringen av ett samhälle i kris. Bilden av ett samhälle präglat av otrygghet och rädsla blir central som grund för möjligheten att föra en mer populistisk politik. (Crouch 2011; Mair 2013; Marsdal 2013; Moffit 2016; Müller 2016).

Att kriminalpolitiken skulle följa den allmänna politiken är då inte ett särskilt djärvt påstående. Här innebär det dock att tyngdpunkten i förklaringen till förskjutningen av kriminalpolitiken förläggs till politikerna och inte till folket. Politikens förändring generellt påverkar också kriminalpolitiken som blir alarmistisk, känslomässig och inriktad på individuell moral och på straff av enskilda individer. Kriminalpolitiken blir också ett område som framstår som särskilt lämpat för att driva en populistisk politik.

\section{Kriminalpolitiken i riksdagsvalet 2018}

Riksdagsvalet 2018 blev det historiskt mest utpräglade lag och ordning-val som ägt rum i Sverige. Det kanske kan ses som något tillfälligt som med lite perspektiv kan ges en egen förklaring. Valkampanjer kan dock innebära att politiska tendenser accentueras särskilt starkt och ge material för analys av även längre trender. Det kan därför finnas skäl att kort granska partiernas kriminalpolitiska budskap 2018.

Valkampanjen sker mot bakgrund av trygghet som det övergripande temat för politiska löften. Begreppet har blivit centralt i den kriminalpolitiska retoriken, och Garland pekade redan i sin analys på att allmänhetens skydd alltmer har hamnat $\mathrm{i}$ centrum för debatten. Robert Andersson gör i en analys från 2002 samma konsta- 
terande för Sverige, och Klara Hermansson (2018) ser kraven på trygghet från brott växa sig allt starkare i politiken. De politiska partierna skiljer sig här heller inte från varandra. Socialdemokraterna benämner sitt kriminalpolitiska program från 2013 Ett tryggare Sverige - och tar titeln rakt av från den borgerliga Alliansens program (Socialdemokraterna 2013; Allians för Sverige 2006).

De konkreta förhållanden som fått politikerna att tala om ökad otrygghet på grund av brott är dels gängrelaterade skjutningar, dels resultat från surveyundersökningar om brott och oro för brott. Sedan 2013 har ett stort antal skjutningar varav många med dödlig utgång ägt rum i de större städernas fattigare och invandrartäta förorter. Från samma områden rapporteras också bilbränder, öppen narkotikahandel, attacker på blåljuspersonal och förtyck av kvinnor som inte följer strikta islamska uppföranderegler. Sedan ett par år visar också Brottsförebyggande rådets (Brå) så kallade trygghetsundersökning en tydlig uppgång i både rapporterade brott mot enskild person och oro för brott efter en tidigare svag nedgång under flera år (Brå 2018).

Med hänvisning särskilt till skjutningarna och trygghetsundersökningarna har partierna formulerat sig mer övergripande om brott som orsak till otrygghet. I valrörelsen framför det största regeringspartiet, Socialdemokraterna: »Oron för brott och kriminellas framfart påverkar hela samhället och arbetslivet, förtroendet vi känner för rättsapparaten och tilliten människor emellan«. Moderaterna skriver: »Utsattheten för sexualbrott ökar och allt fler kvinnor känner sig otrygga«, Centerpartiet anför i sitt valmanifest som skäl för ökade resurser att »polisen och rättsväsendet är det yttersta skyddet för människors fri- och rättigheter«. Liberalerna anser att »alla brott begränsar friheten « och att »rättsstaten måste återupprättas«. Och Sverigedemokraterna har som ingress till sina kriminalpolitiska förslag »Ett tryggt Sverige«. ${ }^{2}$

Denna upptagenhet med hotet från brottsligheten tar sig även uttryck i konkreta förslag på en skärpt kriminalpolitik. Nästan alla partier vill ta bort »straffrabatten« vid flera brott i en dom, slopa straffreduktionen för 18-20-åringar och höja straffen för våldtäkt där lagen har utvidgats sex gånger sedan 1980-talet. Generellt anses straffen inte stå i proportion till brotten och måste därför höjas. Antalet livstidsstraff för mord ska flerfaldigas. Alla partierna uttalar sig för fler poliser och upp till 10000 nya tjänster utlovas.

Politikernas upptagenhet med lag och ordning i valkampanjen kan då ses som att partierna reagerar på en faktisk ökning av brott och att »de tar människors oro

2. Citaten från respektive partis hemsidor under valkampanjen. 
på allvar«. Kraven sägs komma från folket, och politikerna definierar sedan lösningen på problemet i termer av mer strafflagstiftning och ökade resurser och befogenheter till rättsväsendet. Valkampanjen kan då enligt Kathrine Beckett (1997) ses som ett exempel på democracy-at-work - en förklaring som Becket själv på empiriska grunder avvisar.

Frågan är dock om det är så enkelt. Att medborgarna oroar sig för de gängrelaterade skjutningarna är mycket begripligt. Dessa brott är samtidigt tydligt begränsade till vissa grupper och områden. Den ökande rädslan för brott $\mathrm{i}$ hela landet som rapporteras i Brås trygghetsundersökningar (Brå 2018) är samtidigt svår att tolka. Ökningen i den uppgivna utsattheten har heller inte någon motsvarighet i brott rapporterade till polisen. Det gäller särskilt sexualbrotten som på bara några år mer än trefaldigats i intervjuundersökningarna (Tham 2019). I ett något längre perspektiv har som nämnts brottsligheten stagnerat eller gått tillbaka.

Vad som dock är tydligt är att under de år som Brås undersökningar rapporterar en ökning av brott och oro, stiger rapporteringen markant i pressen om trakasserier, sexuella övergrepp och otrygghet. Partiledarna producerar också tillsammans alltfler uttalanden om brott i pressen (Tham, op.cit.).

Beskrivningarna av brottsutvecklingen liksom lösningsförslagen i termer av mer strafflagstiftning, polis och fängelse formuleras också i en situation av allmän oro. Omvärlden är otrygg: ett EU som knakar i fogarna, ett stort populistiskt parti i Sverige liksom i nästan alla europeiska länder, ett mindre stabilt militärt läge i Sveriges närområde, krig vid Europas gräns och ett stort flyktingtryck.

I ett sådant läge kan frågor om brott och straff framstå som något konkret som oron kan kanaliseras mot. Medborgarna kan tänkas lättare anamma alarmistiska kriminalpolitiska budskap när de inte har förstahandskunskap om brottsutvecklingen. Medborgarna måste reagera på information från media, experter och politiker. De politiska partierna både bidrar till och exploaterar rädslan för brott. Kraven på lag och ordning kommer snarare uppifrån än nedifrån.

\section{Straff-välfärdsstaten som kontrollkultur?}

Utvecklingen skulle då kunna ses som en omorientering i svensk kriminalpolitik som den beskrivits av Garland, från straff-välfärdsstat till ökad straffrättslig kontroll. Detta är dock inte detsamma som att påstå att det uppstått en kontrollkultur. Tillgängliga data som skulle stödja Garlands kulturtes saknas för Sverige. Däremot kan det kanske hävdas att andra sidor av straff-välfärdsstaten kommer fram i en förändrad politisk situation. Välfärdsstaten kan tänkas bidra till ökad kontroll genom att a) likställa staten med samhället, b) sträva efter det perfekta samhället utan avvikelser, c) intervenera vid varje typ av socialt problem, och d) 
definiera brott som hot mot välfärden. Dessa tendenser kan illustreras med uttalanden från välfärdstatspartiet par excellence, socialdemokraterna, som också särskilt representerar straff-välfärdsstaten.

Brott blir i socialdemokraternas kriminalpolitiska program något som utgör en attack på vårt samhälle som vi gemensamt måste arbeta mot. Brottsligheten framställs som »ett hot mot hela det demokratiska samhället ...«.»Den organiserade brottsligheten har växt och tagit sig djupare in i samhället, ...«» »Oron för brott och kriminellas framfart påverkar hela samhället ...«»Förtroendet för våra myndigheter måste stärkas ... « och »... de som är mest brottsaktiva måste bort från våra gator «. (Socialdemokraterna 2018a; 2018b). ${ }^{3}$ Vi har också, enligt socialdemokraterna, ett gemensamt ansvar för att bekämpa brottsligheten, »att hela samhället involveras i det brottsförebyggande arbetet « - något som också visar sig i titeln på tidigare kriminalpolitiska program, Allas vårt ansvar (Ds 1996:59) och Tillsammans mot brott (Regeringens skrivelse 2016/17:126). Brott förstås alltmer i en durkheimsk mening, som något som utgör en attack på en gemensam rättskänsla och som därför blir särskilt allvarligt och måste bemötas med kraft.

Det bästa kan bli det godas fiende. I socialdemokraternas program finns exempel på uttalanden om långtgående åtgärder för att få bort alla eller de flesta brott - uttalanden som samtidigt måste betraktas som orealistiska. »Unga ska inte begå brott eller befinna sig i sammanhang där brott begås. « »Därför måste samhället reagera tydligt mot brott och regelöverträdelser. Straff ska vara kännbara och upptäcksrisken stor.« Betoningen av samhället som utsätts för brott och kraven på att alla brott ska bekämpas riskerar också att komma i konflikt individens rättigheter. Vanessa Barker (2013) har framhållit hur den svenska välfärdsstaten i folkets och samhällets namn kan gå långt $i$ tvångsingrepp mot medborgarna.

Det tydligaste exemplet på nolltolerans mot brott är kriminaliseringen av själva konsumtionen av narkotika, något som nästan alla riksdagspartier står bakom med parollen »Sverige narkotikafritt samhälle«. Polisen tar närmare 40000 prov av kroppsvätskor per år för att söka spår av narkotika som inte manifesterar sig i något brottsligt handlande. Socialdemokraterna har uttryckligen sagt sig inte vilja se över denna lagstiftning eller velat förklara vad staten har i medborgarnas urin att göra. Denna strävan efter »det rena samhället« har också kommit till uttryck i 2018 års valrörelse vad gäller tiggeri. Socialdemokraterna nöjer sig här med att

3. Citaten har hämtats från socialdemokraterna, Kriminalpolitiskt program, https://www.social demokraterna.se/var-politik/a-till-o/lag-och-ordning/ och https://www.socialdemokraterna.se/ var-politik/a-till-o/lag-och-ordning/. Kursiveringarna tillagda här. 
vilja minska möjligheten till tiggeri medan Moderaterna och Sverigedemokraterna vill införa ett totalförbud (Advokaten 2018). I narkotikapolitiken har också en skiljefråga inom socialismen visat sig, den om synen på »trasproletariatet«, som sedan länge präglat svensk arbetarrörelse (Pedersson 2005).

Oviljan att tolerera brott, avvikelser och sociala problem, som naturligtvis i långa stycken är lovvärd, sammanhänger också med socialdemokraternas och välfärdsstatens tradition av social ingenjörskonst och intervention. För ett ickerevolutionärt socialistiskt parti står reformer och strävan att ställa till rätta i centrum. Det är helt enkelt svårt för socialdemokrater att underlåta att gripa in.

Denna reformiver har tidigare haft stort utrymme på det ekonomiska området. En hypotes skulle då kunna vara att när detta utrymme minskar genom att de ekonomiska besluten alltmer flyttat till Bryssel och den globala marknaden, kan reformivern och önskan att ingripa tänkas koncentreras till moralfrågor som brott och straff. I de angloamerikanska länderna, där politiken vanligen baseras på tvåpartisystem, är den partipolitiska skillnaden i ekonomisk politik och fördelningsfrågor ofta liten. Partierna, och särskilt de till höger, tenderar därför att konkurrera om väljarna på moralfrågor (Lipset 1966, s. 219 f.; Lenke 1980, s. 23). Dessa länder är i ett jämförande perspektiv de mest straffinriktade (Tham 2005; LappiSeppälä 2014). Den expressiva kriminalpolitiken kan också, i en situation av minskat reformutrymme, fungera som ett sätt att försöka återupprätta statens och politikernas auktoritet, framhåller Garland (2001, s. 131 ff.).

Nils Jareborg (1995) har beskrivit en rörelse i strafflagstiftningen från vad han benämner en defensiv till en offensiv modell. Den förra är den klassiskt juridiska med starka rättssäkerhetskrav, begränsning av strafflagstiftning och synen på fängelse som något som ska tas till först $\mathrm{i}$ sista hand. Den offensiva modellen däremot ser, enkelt uttryckt, strafflagstiftning som ett medel för att bekämpa sociala problem. Denna modell kan också ses som väl anpassad för välfärdsstatens reformsträvanden och resulterar i en expanderande strafflagstiftning. Detta har skett i Sverige i accelererande takt under både borgerliga och socialdemokratiska regeringar (Tham 2018, s. 82 f.).

Slutligen, välfärdsstatens exkluderande snarare än solidariska och inkluderande sida har också uppmärksammats. Välfärden för dem inom systemet har i tilltagande grad framställts som hotad av människor utanför. Vanessa Barker (2018) har framhållit denna aspekt vad gäller den svenska flyktingpolitiken. Sverigedemokraterna ställer tydligt välfärd för pensionärerna mot flyktingmottagande. Carsten Jensen (2018) kommenterar den svenska politiska utvecklingen med hänvisning till den danska och europeiska diskursen om välfärdsstaten som enligt politikerna kommer att bryta samman under trycket från flyktingströmmarna. 
Denna sida av välfärdsstatspolitiken kommer tydligt till uttryck i socialdemokraternas kriminalpolitiska program 2013. Tidigare var brott och missbruk symptom på brister i uppväxten och samhället. Även de avvikande, de marginaliserade och de utslagna skulle omfattas av stöd och solidaritet och hjälpas till ett bättre liv. Kraven på trygghet innebar trygghet från ett liv i brott och missbruk. I det nya programmet heter det i stället: »Till välfärdspolitiken hör också trygghet mot brott« (Socialdemokraterna 2013, s. 7). Med denna formulering kan mer strafflagstiftning, polis och fängelse berättigas genom hänvisning till allmänhetens välfärd. I socialdemokraternas kriminalpolitiska program under rubriken »lag och ordning « inför valet 2018 presenterade partiet 14 löften om utvidgade straff- och tvångsåtgärder (Socialdemokraterna 2018).

Också Garland framhåller straff-välfärdsstatens kontrollerande sida. Peter Scharff Smith och Thomas Ugelvik (2017) talar i en analys av straff i de skandinaviska välfärdsstaterna om The Big Mother penal welfare state model. I de skandinaviska länderna präglade av stor konsensus och med högt förtroende kan rehabilitering med tvång ses som en naturlig del av välfärdsstaten, och intoleransen mot avvikelser i den goda staten framstå som berättigad (op.cit., s. 513).

Den välfärdsstatliga traditionen verkar alltså kunna både begränsa och utvidga en straffinriktad kriminalpolitik. Utvecklingen av kriminalpolitiken i Sverige förefaller inte vara oförenlig med delar av straff-välfärdsstatens ideologiska grund. Denna utveckling bör dock ses som ett uttryck för olika potential i en politisk struktur snarare än som en folkligt driven kulturförändring.

\section{Litteratur}

Advokaten. (2018). Tidskrift för Sveriges advokatsamfund, 84 (6).

Allians för Sverige. (2006). Ett tryggare Sverige. Förslag från Allians för Sveriges rättspolitiska grupp, 2006-02-22.

Andersson, R. (2002). Kriminalpolitikens väsen. Ak. avh. Stockholm: Kriminologiska institutionen, Stockholms universitet.

Balvig, F., Gunlaugsson, H., Jerre, K., Kinnunen, A. \& Tham, H. (2015). The Public Sense of Justice in Scandinavia: A Study of Attitudes towards Punishment. European Journal of Criminology, 12(3), s. 342-361.

Barker, V. (2013). Nordic Exceptionalism Revisited: Explaining the Paradox of a Janus-faced Penal Regime. Theoretical Criminology, 17(1), s. 5-25.

Barker, V. (2018). Nordic nationalism and penal order. Walling the welfare state. London \& New York: Sage.

Beckett, K. (1997). Making crime pay. Law and order in contemporary American politics. New York: Oxford University Press.

Brå. (1977). Nytt straffsystem. Idéer och förslag. Rapport 1977:7. Stockholm: Brottsförebyggande rådet. 
Brå. (2018). Nationella trygghetsundersökningen 2017. Om utsatthet, otrygghet och förtroende. Rapport 2018:1. Stockholm: Brottsförebyggande rådet.

Crouch, C. (2011). Postdemokrati. Göteborg: Daidalos.

Ds 1996:59. Allas vårt ansvar. Ett nationellt brottsförebyggande program. Stockholm: Justitiedepartementet/Fritzes.

Garland, D. (2001). The culture of control. Crime and social order in contemporary society. Oxford: Oxford University Press.

Hermansson, K. (2018). Den svenska tryggheten. En studie av en kriminalpolitisk symbol. Sociologisk forskning, 55 (2-3), s. 179-202.

von Hofer, H. \& Tham, H. (2013). Punishment in Sweden: A Changing Penal Landscape. I V. Ruggerio \& M. Ryan, red., Punishment in Europe. A critical anatomy of penal systems. Basingstoke, UK: Palgrave MacMillan, s. 33-57.

Jareborg, N. (1995). Vilken sorts straffrätt vill vi ha? - Om defensiv och offensiv straffrättspolitik. I: D. Victor, red., Varning för straff. Om vådan av den nyttiga straffrätten. Stockholm: Norstedts Juridik, s. 19-37.

Jensen, C. (2018). Så förrådde S sina egna väljare. Dagens Nyheter, 2018-08-30.

Jerre, K. \& Tham, H. (2010). Svenskarnas syn på straff. Rapport 2010:1. Stockholm: Kriminologiska institutionen, Stockholms universitet.

Lappi-Seppälä, T. (2014). Imprisonment and Penal Demands: Exploring the Dimensions and Drivers of Systemic and Attitudinal Punitivity. I: S. Body-Gendrot, M. Hough, K. Kerezsi, R. Lévy \& S. Snacken, red., The Routledge Handbook of European Criminology. London: Routledge.

Lenke, L. (1980). Criminal Policy and Repression in Capitalist Societies - The Scandinavian Case. I: R. Hauge, red., Scandinavian Studies in Criminology, vol. 7. Oslo: Universitetsforlaget.

Lipset, S. (1966). Den politiska människan. Studier i politikens sociologi. Stockholm: Aldus/ Bonnier.

Loader, I. \& Sparks, R. (2011). Public criminology. London: Routledge.

Mair, P. (2013). Ruling the void. The hollowing of western democracy. London: Verso.

Marsdal, M. (2007). Högerpopulismen dissekerad. Lund: Celanders.

Moffit, B. (2016). The global rise of populism. Performance, political style and representation. Stanford: Stanford University Press.

Müller, J.-W. (2016). What is populism? Philadelphia: University of Pennsylvania Press.

Pedersson, A. (2005). Den tidiga svenska socialdemokratins syn på arbetarklassens nedersta skikt. Masteruppsats. Stockholm: Institutionen för litteraturhistoria och idéhistoria, Stockholms universitet.

Pollack, E. (2001). En studie i medier och brott. Ak. avh. Stockholm: Institutionen för journalistik, medier och kommunikation, Stockholms universitet.

Pratt, J. (2007). Penal populism. London: Routledge.

Regeringens skrivelse, Skr. 2016/17:126, Tillsammans mot brott. Ett nationellt brottsförebyggande program. Stockholm: Riksdagens tryckeriexpedition.

Schwartz, J.A. \& Hammarlund, J. (2018). Bilder av mord - presstexter om dödligt våld i Sverige 2001-2017. I: J.A. Schwarz, P. Frigyes, J. Hammarlund, B. Johansson, P. Rapacioli, H. Selin 
\& J. Stenberg. Sverigebilden - om journalistik och verklighet. Stockholm: Institutet för mediestudier.

Smith, P.S. \& Ugelvik, T. (2017). Punishment and welfare in Scandinavia. I: P.S. Smith \& T. Ugelvik, red., Scandinavian penal history, culture and prison practice. Embraced by the welfare state? Basingstoke: Palgrave MacMillan.

Socialdemokraterna. (2013). Ett tryggare Sverige. Bekämpa brotten och brottens orsaker. Kriminalpolitiskt program för socialdemokraterna 2013.

Socialdemokraterna. (2018a). Kriminalpolitiskt program, 2018-06-17 https://www.social demokraterna.se/globalassets/aktuellt/kriminalpolitiskt-program-2018-06-07.pdf [hämtad 2018-11-26].

Socialdemokraterna. (2018b). Lag och ordning, https:/www.socialdemokraterna.se/var-politik/ a-till-o/lag-och-ordning/ [hämtad 2018-11-26].

Tham; H. (2005). Imprisonment and inequality. Konferensbidrag till 5 th annual conference of the European Society of Criminology, Kraków, 31 augusti-3 september, 2005.

Tham, H. (2018). Kriminalpolitik. Brott och straff $i$ Sverige sedan 1965. Stockholm: Norstedts Juridik.

Tham, H. (2019). Oro för brott och den offentliga diskursen. I: A. Heber \& L. Roxell, red., Att odla kriminologi. Perspektiv på brott och utsatthet. Festskrift till Eva Tiby. Stockholm: Kriminologiska institutionen, Stockholm Universitet.

Tonry, M. (2014). Why Crime Rates are Falling throughout the Western World. I: M. Tonry, red., Why crime rates fall and why they don't. Crime and Justice. A Review of Research, vol. 43. Chicago: The University of Chicago Press. 